\title{
Quality of Life (QoL) as Predictive Mediator Variable for Survival in Patients with Intracerebral Neoplasma During Radiotherapy
}

\author{
S. Sehlen ${ }^{\mathrm{a}}$ \\ M. Lenk ${ }^{a}$ \\ H. Hollenhorst ${ }^{a}$ \\ B. Schymura ${ }^{a}$ \\ U. Aydemirb \\ P. Herschbachc \\ E. Dühmke \\ a Department of Radiotherapy and Radiooncology, \\ b Institute for Biometry and Epidemiology, Klinikum Großhadern, Ludwig Maximilians University, \\ ${ }^{c}$ Institute and Polyclinic for Psychosomatic Medicine, Psychotherapy and Medical Psychology, Technical University, Munich, Germany
}

\section{Key Words}

Quality of life · FACT-G · Radiotherapy · Brain tumours · Survival

\section{Summary}

Background: The prognosis for patients with malignant astrocytoma or brain metastases is often fatal despite intensive therapy. Therefore we wished to elucidate whether the quality of life ( $\mathrm{QoL}$ ) is a determinant of overall survival (OAS). Patients and Methods: From 1997 to 2000153 patients with brain tumours were screened; 39 patients $(26 \%)$ refused to participate and further 47 patients were excluded (cerebral impairment 14\%, amaurosis/language problems 3\%, Karnofsky performance score $<50 \% 7 \%$, death $8 \%$, non-compliance $7 \%$ ). Thus, 57 patients were analysed (33 with primary brain tumours, 24 with brain metastases). With the FACT-G questionnaire cancer-specific aspects of health-related QoL were assessed. Results: Patients with metastases showed a lower QoL in the physical sphere than patients with astrocytoma, but there were no significant differences in OAS. Median survival of patients with good QoL was 31.3 months versus 14.2 months in patients with bad OoL. Only the two variables 'living with a spouse' and FACT-G sum score had a statistically significant influence on survival ( $p=0.033$ and $p=0.003$ ) modelled by the Cox-PH regression. Patients who did not live with a spouse had shorter survival times than the other patients. Conclusion: Health-related QoL can serve to identify a patient group with higher risks of death.
Schlüsselwörter

Lebensqualität · FACT-G · Strahlentherapie ·

Hirntumoren · Überleben

\section{Zusammenfassung}

Hintergrund: Die Prognose von Patienten mit malignen Astrocytomen und Hirnmetastsen ist, trotz intensiver Therapie, oft fatal. Ziel dieser Studie war es deshalb zu untersuchen, ob die Lebensqualität ( $\mathrm{OoL}$ ) einen Einfluss auf das Überleben zeigt. Patienten und Methode: Von 1997 bis 2000 wurden 153 Patienten untersucht. 39 (26\%) lehnten eine Teilnahme an der Studie ab, 47 wurden ausgeschlossen (14\% cerebrales Unvermögen, 3\% Sprachprobleme, 7\% Karnofsky Index < 50\%, 8\% Tod, 7\% keine Compliance). 57 Patienten waren auswertbar (33 mit primären Hirntumoren, 24 mit Hirnmetastasen). Mit dem FACT-G Fragebogen wurden krebsspezifische Aspekte der QoL gemessen. Ergebnisse: Patienten mit Hirnmetastasen zeigten im körperlichen Bereich eine niedrigere QoL als Patienten mit Astrocytomen; Unterschiede im Überleben von Patienten konnten zwischen beiden Gruppen nicht erkannt werden. Das mediane Überleben von Patienten mit einer guten QoL betrug 31,3 Monate vs. 14,2 Monate von Patienten mit schlechter QoL. Nur die zwei Variablen "Leben mit Angehörigen» und der FACTG Summenwert zeigten bei der Modellierung mit einer Cox-PH Regression einen signifikanten Einfluss ( $p=$ 0,033 and $p=0,003$ ) auf das Überleben. Patienten, die nicht mit Angehörigen zusammenlebten, hatten eine kürzere Überlebenszeit als die anderen Patienten. Schlussfolgerung: OoL kann dabei helfen, Patientengruppen mit einem höheren Sterberisiko zu identifizieren.

\begin{tabular}{ll}
\hline KARGER & ( ) 2003 S. Karger GmbH, Freiburg \\
Fax +497614520714 & Accessible online at: \\
$\begin{array}{l}\text { E-mail Information@Karger.de } \\
\text { www.karger.com }\end{array}$ & www.karger.com/onk
\end{tabular}




\section{Background}

The prognosis for malignant astrocytoma, especially for glioblastoma multiforme, as well as for brain metastases of different other primaries is fatal in most cases despite intensive therapy. Current possible therapy options are surgery and external beam radiotherapy. Chemotherapy and more special techniques such as radiosurgery or implantation of radioactive devices are not yet part of widely used standard treatment protocols. Therapy is usually designed to prolong patients' survival and often has no curative intent. Thus, not only the duration of survival alone but also the quality of life (QoL) of these patients is an important end-point when it comes to making decisions about a therapy regimen. Faller et al. [1] and other investigators have already shown that the psychological state, i.e. emotional well-being, depressive symptoms and coping methods of the patient, has an influence on survival [2-4]. There has been little published research, however, on the health-related QoL of high-grade astrocytomas. Most of the few existing studies do not use validated or cancer-specific QoL instruments but rely on performance indices, self-developed instruments, neuropsychological testing instruments (e.g. the Mini Mental State Inventory, MMSI), opinion of treating physicians or interviews instead [5-7]. Other recent work did use validated testing instruments but merely described the results without the effort to use them to improve current clinical practice [8-10]. Our primary hypothesis was that patients with a below-average QoL could be at risk for an earlier death. Second, we presumed that in this final stage of disease, medical variables are not as important as usually considered. In this study, we wish to elucidate whether QoL, assessed with a validated QoL instrument, is a determinant of survival.

\section{Patients and Methods}

All patients were treated at the Department of Radiotherapy and Radiooncology at Klinikum Grosshadern Ludwig Maximilian University, Munich. The patients were asked to fill in the following 2 questionnaires at the beginning of their radiotherapy:

The self-developed Current Situation in Personal Life questionnaire (LS) assessed important sociodemographic variables and parameters in the personal life of the patients. They were asked to supply information about marital status, whether or not they were living with a spouse or with friends, the number of children, and the number of persons in the household. Furthermore, the instrument assessed the levels of secondary and professional education, the current type of employment and the current capacity to work in categories like doing one's job part-time, full-time or being temporarily or permanently off work due to medical reasons.

As far as the disease was concerned, patients were asked about the incidence of cancer in their family history, about the first symptoms of their disease and whether they had someone to look after them.

Additional items taken into account were the patients' relationships with friends, their hobbies, their religion and spirituality, their social life and peer groups. Patients were asked to supply information about what they considered to be significant events in the previous two weeks and in the preceding year.

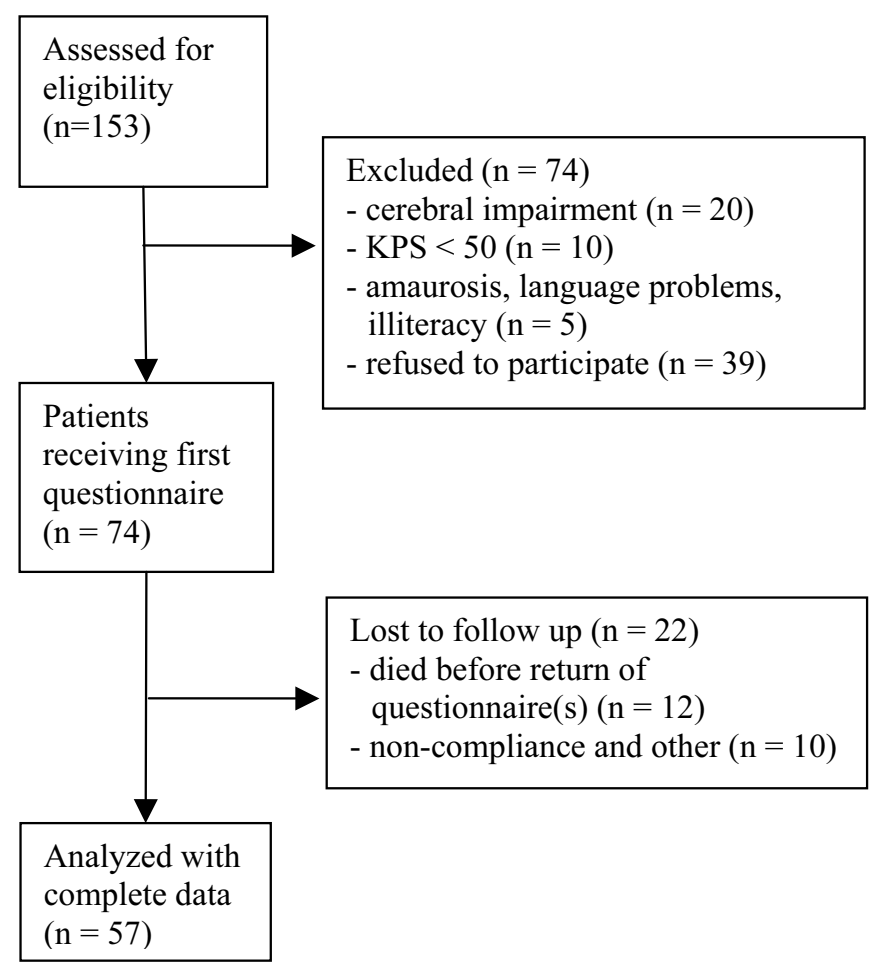

Fig. 1. Patients' course from screening to evaluation (CONSORTcriteria).

The Functional Assessment of Cancer Therapy - General (FACT-G), version 3 questionnaire was developed to assess cancer-specific aspects of health-related QoL with good overall results for reliability and validity [11]. The Fact-G count of 5 subscales evaluated physical (0-28 pts), social and family (0-28 pts), emotional (0-20 pts) and functional well-being ( $0-28 \mathrm{pts})$ and the patients' relationships with doctors ( $0-8 \mathrm{pts})$. These various QoL domains were assessed as a function of treatment with 29 items each being scored in 1-5 categories. This resulted in an overall score ranging from 0-112 pts. Although there is a module specific for brain cancer patients (FACT-BR) which could have been used for patients with primary brain tumours [12], we omitted this additional module because there was no information about the use of this instrument for patients with brain metastases. Medical data were obtained from the hospital files.

Patients were eligible for the study if they suffered from a malignant intracranial neoplasma which required external beam radiotherapy. They had to be at least 18 years of age and to understand and read German properly. They had to be physically and mentally able to fill out the questionnaire without any help of others. Mental capacity was assessed by a modified abbreviated version of the MMSI; physical state was assessed by the Karnofsky performance index. Patients had to have a Karnofsky performance score (KPS) of 50 or above to be eligible for the study. Patients suffering from a second disease of any kind with an infaust prognosis were excluded. Thus, none of the study patients died from any other cause than the tumour they were suffering from.

The questionnaires were handed to the patients before their first fraction was delivered. Patients were explained the aims of the study, were informed about the way the questionnaire data should be evaluated and that participation in the study and their therapy were not at all linked. They were then asked to give written informed consent and to fill out the questionnaires in the following 7 days. The second visit was after the last irradiation dose had been delivered. Patients were handed out the second set of questionnaires and were again motivated to continue participating in the study. The third point of measurement was 6 weeks after completion 
Table 1. Sociodemographic and medical data of patients

\begin{tabular}{|c|c|c|c|c|}
\hline & CNS p & ry $(n=33)$ & $\mathrm{Me}$ & $(\mathrm{n}=24)$ \\
\hline Age, years & & & & \\
\hline Median & 51 & 52.5 & & \\
\hline Range & $21-83$ & $29-78$ & & \\
\hline & $\mathrm{n}$ & $\%$ & $\mathrm{n}$ & $\%$ \\
\hline $18-55$ & 21 & 63.6 & 15 & 62.5 \\
\hline$>55$ & 12 & 36.4 & 9 & 37.5 \\
\hline Sex & & & & \\
\hline Female & 10 & 30.3 & 12 & 50.0 \\
\hline Male & 23 & 69.7 & 12 & 50.0 \\
\hline Karnofsky Performance & Score & & & \\
\hline$<80$ & 11 & 33.3 & 12 & 50.0 \\
\hline $90-100$ & 22 & 66.7 & 12 & 50.0 \\
\hline Primary tumour & & & & \\
\hline Lung cancer & & & 9 & 37.5 \\
\hline Colon cancer & & & 1 & 4.2 \\
\hline Gall bladder cancer & & & 1 & 4.2 \\
\hline Malignant melanoma & & & 1 & 4.2 \\
\hline Testicular cancer & & & 3 & 12.5 \\
\hline Laryngeal cancer & & & 1 & 4.2 \\
\hline Breast cancer & & & 5 & 20.8 \\
\hline CUP & & & 2 & 8.3 \\
\hline Soft tissue sarcoma & & & 1 & 4.2 \\
\hline Surgery & & & & \\
\hline No & 6 & 18.2 & 10 & 41.7 \\
\hline Yes & 27 & 81.8 & 14 & 58.3 \\
\hline Chemotherapy & & & & \\
\hline No & 33 & 100.0 & 11 & 45.8 \\
\hline Yes & & & 13 & 54.2 \\
\hline Relapse therapy & & & & \\
\hline No & 26 & 78.8 & 23 & 95.8 \\
\hline Yes & 7 & 21.2 & 1 & 4.2 \\
\hline Marital status & & & & \\
\hline Single & 8 & 24.2 & 6 & 25.0 \\
\hline Married & 23 & 69.7 & 14 & 58.3 \\
\hline Other & 2 & 6.1 & 4 & 16.7 \\
\hline Living with a spouse & & & & \\
\hline No & 7 & 21.2 & 7 & 29.2 \\
\hline Yes & 26 & 78.8 & 17 & 70.8 \\
\hline Health insurance & & & & \\
\hline State & 12 & 36.4 & 16 & 66.7 \\
\hline Private & 21 & 63.6 & 8 & 33.3 \\
\hline Level of secondary educ & cation & & & \\
\hline None/low & 7 & 26.9 & 7 & 38.9 \\
\hline Medium & 6 & 23.1 & 7 & 38.9 \\
\hline High & 13 & 50.0 & 4 & 22.2 \\
\hline Professional education & & & & \\
\hline Non-academic & 16 & 59.3 & 13 & 59.1 \\
\hline Academic & 11 & 40.7 & 9 & 40.9 \\
\hline Hospitalisation & & & & \\
\hline Outpatient & 14 & 42.4 & 11 & 45.8 \\
\hline Inpatient & 19 & 57.6 & 13 & 54.2 \\
\hline
\end{tabular}

of the radiation therapy. Since most patients had then left the clinic, the questionnaires were mailed to the patients with a free return envelope included. All 3 questionnaire batteries included a letter which repeated the main points of the study. It was stated clearly and repeatedly that participation was completely voluntary and would not at all influence therapy or follow up. During the period of recruitment (December 1997 - October 2000), 153 patients with cerebral irradiation were screened. 39 patients $(25.5 \%)$ refused to participate, a further 47 patients were excluded because they did not meet the inclusion criteria, 10 patients did not return their questionnaires. This resulted in 57 eligible patients with complete data (fig. 1). 33 Patients suffered from primary brain malignoma; 11 had grade III astrocytoma and 18 glioblastoma multiforme, 4 had primary brain tumours of different histology. 24 patients were irradiated for brain metastases of an extracerebral primary tumour. Table 1 lists the various tumour diagnoses and the sociodemographic data of the patients. Patients had a median age of 52 years, ranging between 21 and 83 years. Non-participants had a median age of 61 years (ranging between 21 and 83 years), $48.5 \%$ of them were females. Their median KPS score was 70 .

To ensure that our analysis was not influenced by selection bias, the distribution of patients into participants and non-participants was assessed by means of the chi-square test. None of the medical variables turned out to differ significantly between the two groups. The only exception was KPS; significantly more patients with a KPS of 80 and below refused to participate in our study. On the one hand, this was mostly a result of the inclusion criteria which explicitly excluded patients with a KPS below 50. On the other hand, this phenomenon was frequently seen in QoL investigations and thus should not diminish the validity of our results.

The data were analysed with the Kaplan-Meier analysis and the Cox regression analysis using the statistical package SPSS ${ }^{\circledR}$ for Windows version 10.0 .

\section{Results}

Results of the FACT-G QoL measurement were calculated for the whole group of patients and are shown in table 2 . The results are markedly lower than the ones previously described in the literature [12]. At the initial point of assessment, we found a markedly lower QoL in the physical sphere for patients with brain metastases which resulted in a lower overall QoL for patients with metastases (22.6 vs. 16.9). There were no differences in other subscales between these two groups, neither in any of the other subscales nor at the other points of assessment (table 2).

Patients with primary brain tumours had a median survival of 26.4 (95\% CI $=13.96-38.84)$ months, which is comparable to the median survival of 28.3 (95\% CI $=0-58.85)$ months for patients with brain metastases. There was no statistically significant difference between the survival curves (log rank test, $\mathrm{p}=0.86$ ). The other striking fact was that in contrast to clinical experience and the findings in the literature, the survival times seemed unexpectedly long. The reason for this is that our completely unselected patient sample contained $34.4 \%$ anaplastic astrocytomas and $12.5 \%$ brain tumours of a different histological origin. Figure 2 shows the survival curves for both groups.

We were further encouraged by this result to look for another factor that would show some influence on our patients' survival. We suspected that health-related quality of life might be 
Table 2. Distribution of HRQoL-measurement with FACT-G; in patients with primary brain tumours and brain metastases

\begin{tabular}{|c|c|c|c|c|c|c|c|c|c|}
\hline & & \multicolumn{2}{|c|}{ CNS primary $(n=33)$} & \multicolumn{2}{|c|}{ CNS metastases $(n=24)$} & \multicolumn{2}{|c|}{ Whole sample } & \multirow[t]{2}{*}{ F value } & \multirow[t]{2}{*}{ p-Value } \\
\hline & & mean & SD & mean & SD & mean & SD & & \\
\hline \multirow[t]{3}{*}{ Physical well-being } & before therapy & 22.56 & 5.10 & 16.93 & 7.26 & 20.24 & 6.63 & 11.629 & 0.0012 \\
\hline & end of therapy & 18.06 & 7.09 & 16.79 & 6.81 & 17.57 & 6.92 & 0.325 & 0.5717 \\
\hline & 6 weeks after therapy & 21.09 & 6.90 & 17.27 & 6.56 & 19.77 & 6.92 & 2.284 & 0.1412 \\
\hline \multirow[t]{3}{*}{ Family, friends } & before therapy & 21.99 & 5.01 & 20.70 & 3.25 & 21.44 & 4.36 & 1.217 & 0.2747 \\
\hline & end of therapy & 20.10 & 5.65 & 19.61 & 3.79 & 19.91 & 4.97 & 0.091 & 0.7649 \\
\hline & 6 weeks after therapy & 21.63 & 3.65 & 20.44 & 4.04 & 21.21 & 3.76 & 0.713 & 0.4053 \\
\hline \multirow[t]{3}{*}{ Relationship to doctor } & before therapy & 6.52 & 1.57 & 6.71 & 1.43 & 6.60 & 1.49 & 0.219 & 0.6414 \\
\hline & end of therapy & 6.31 & 1.62 & 6.53 & 1.30 & 6.39 & 1.49 & 0.212 & 0.6481 \\
\hline & 6 weeks after therapy & 6.19 & 1.86 & 6.56 & 1.42 & 6.30 & 1.72 & 0.275 & 0.6041 \\
\hline \multirow[t]{3}{*}{ Emotional well-being } & before therapy & 14.17 & 4.55 & 12.33 & 3.36 & 13.38 & 4.15 & 2.786 & 0.1009 \\
\hline & end of therapy & 14.18 & 4.74 & 13.53 & 3.54 & 13.94 & 4.30 & 0.212 & 0.6477 \\
\hline & 6 weeks after therapy & 13.78 & 4.55 & 14.34 & 3.35 & 13.97 & 4.12 & 0.131 & 0.7202 \\
\hline \multirow[t]{3}{*}{ Functional well-being } & before therapy & 17.06 & 6.41 & 14.24 & 5.32 & 15.85 & 6.08 & 3.056 & 0.0861 \\
\hline & end of therapy & 16.55 & 6.77 & 15.27 & 4.68 & 16.08 & 6.06 & 0.421 & 0.5202 \\
\hline & 6 weeks after therapy & 17.33 & 6.51 & 14.62 & 4.45 & 16.40 & 5.95 & 1.528 & 0.2261 \\
\hline \multirow[t]{3}{*}{ Sum score } & before therapy & 82.37 & 15.81 & 71.19 & 14.30 & 77.60 & 16.04 & 7.154 & 0.0100 \\
\hline & end of therapy & 75.20 & 17.11 & 71.97 & 15.96 & 74.01 & 16.56 & 0.355 & 0.5545 \\
\hline & 6 weeks after therapy & 80.02 & 18.75 & 72.64 & 13.33 & 77.80 & 17.41 & 1.138 & 0.2951 \\
\hline
\end{tabular}

Table 3. Prognostic factors for survival by Cox-PH analysis

\begin{tabular}{lllllll}
\hline Prognostic factor & $\begin{array}{l}\text { Maximum } \\
\text { Likelihood }\end{array}$ & Standard error & $\begin{array}{l}\text { Chi-square } \\
\text { test statistic }\end{array}$ & p-Value & Risk ratio & $\begin{array}{l}95 \% \text { Confidence } \\
\text { interval for risk ratio }\end{array}$ \\
\hline FACT-G sum score & -0.048 & 0.016 & 12.460 & 0.003 & 0.953 & $0.923-0.984$ \\
Spouse & 1.691 & 0.793 & 11.158 & 0.033 & 5.426 & $1.146-25.659$ \\
\hline
\end{tabular}

important for patients with lower QoL who might normally have shown lower survival rates.

We wanted to differentiate between good and bad QoL with acceptable sample sizes in both groups. Therefore the cut-off point was drawn along the 40th percentile in the FACT-G sum score values (cut-off point 73 ), which resulted in $33(61.1 \%)$ patients with good and 21 (38.9\%) patients with bad QoL. The background of this choice of cut-off point was a capacity analysis in our department considering the number of physicians with a supplementary training in psychooncology. The result of this analysis was that about $40 \%$ of patients could be subject to an additional psychological intervention. Since our situation in Munich is likely to be similar to other radiooncology departments, we chose this cut-off point to define patients with 'bad QoL'. The median survival of patients with good QoL was 31.3 months vs. only 14.2 months in patients with bad QoL estimated by Kaplan-Meier; log-rank testing revealed a significant result $(\mathrm{p}=0.0039)$ (fig. 3 ).

The next step was to find out whether there were certain factors that could predict survival in our patient sample. Therefore Cox-PH regression was performed with the following potential risk factors: primary tumour (brain/other), surgery (yes/no), medical insurance mode (state/private), comorbidity (number of concomitant diseases), the level of secondary education (none or low/medium/high), level of professional education (academic/non-academic), patient type (inpatient/outpatient), relapse therapy (yes/no), age, KPS, total dose in main radiation field, living with one's spouse (yes/no), sex (male/female), FACT-G sum score.

Only two variables 'living with one's spouse' (yes/no) and FACT-G sum score $(\mathrm{p}=0.033$ and $\mathrm{p}=0.003)$ had significant influence on survival (table 3 ). Living with a spouse and a higher FACT-G sum score was associated with a longer expected survival. It was remarkable that somatic variables did not influence survival.

\section{Discussion}

Of the patients who were approached, $25.5 \%$ refused to participate. However, we had a heterogeneous sample of patients as well as a relatively positive selection of patients as a result of the strict criteria for inclusion. It is not possible to determine how psychologically representative the participants were 


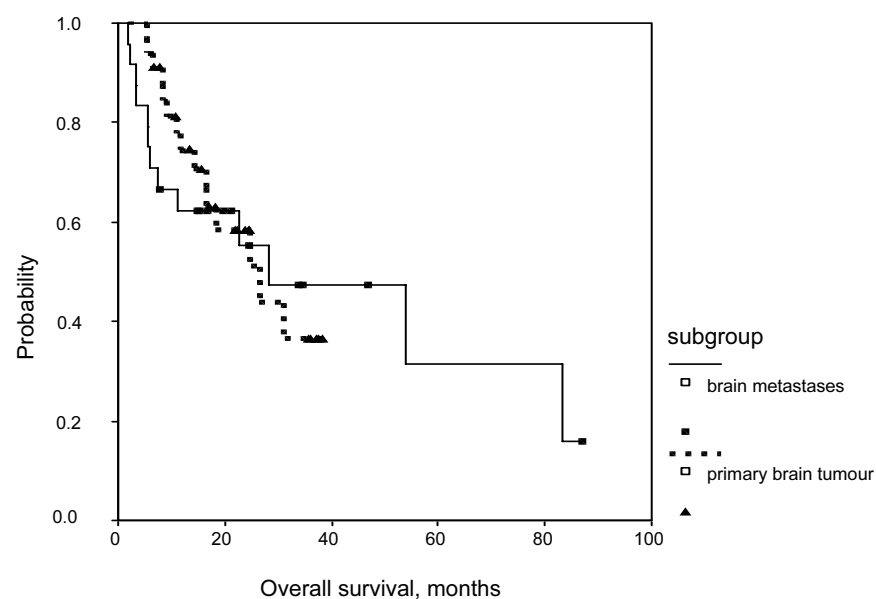

Fig. 2. Survival of brain tumours vs. metastases $(p=0.8630)$.

of all the patients with brain tumours seen in our department. The results of the treatment of patients in one radiotherapy department could possibly be applicable to other hospitals as well. It is reasonable to assume that those who refused to participate were no less psychologically reactive than other patients and that our patient sample was representative of a university radiotherapy department.

We found markedly lower QoL values than previously described in the literature. This might be due to two factors: First, since we only included patients with high-grade gliomas and brain metastases, we chose to work with patients who had a very limited life expectancy. This restricted view of patients who had already arrived at the final stage of their disease seems unique. Thus it is even more important for such patients that measures are taken to improve their QoL as far as possible. Secondly, the fact that we did not work with patients who had primary brain tumours only but also included patients with brain metastases might have contributed to the worse overall QoL. Hence, we investigated whether the FACT-G values for patients with primary brain tumours differed from those for patients with brain metastases.

The difference was significant only at the initial measurement and only in the subscale for physical well-being, and accordingly for the sum score, because this subscale contributes significantly to the whole FACT-G value. At the two latter measurements, no significant differences neither in any of the subscales nor in the sum score could be found (table 2).

From this point of view it seemed possible that patients with primary brain tumours might have a different expected survival than those with brain metastases. However, Log-Rank testing showed no significant difference in survival times.

In contrast, our primary hypothesis that health-related QoL (HRQoL) might influence survival was supported by log-rank testing. This is probably due to our patient selection: Although our patient group was very heterogenous as to type of disease,

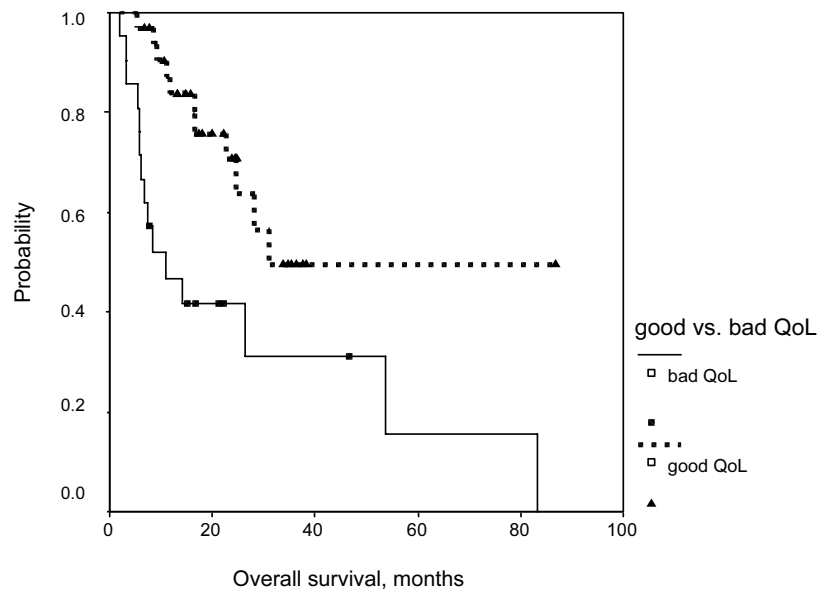

Fig. 3. Survival of patients with good QoL (FACT-G sum score $\geq 70$ vs. bad QoL (FACT-G sum score < 70); $(\mathrm{p}=0.0039)$.

what these patients all had in common was that they were all to die of their disease and so their treatment was only palliative. There were already indications that psychological and sociodemographic variables can influence survival in cancer patients and so we considered a non-selected collective of patients suitable for such an investigation [1,13-16].

One might argue that HRQoL is just a surrogate parameter for the medical state of the individual patient. Several recent studies which focused on various malignant and non-malignant chronic diseases have shown that subjectively perceived quality of life does not directly correlate with the stage and the course of disease [17-21].

Apart from merely illustrating that QoL as a variable independent of the medical condition of the patient, is linked to prolonged survival, we also considered it probable that HRQoL might be among the variables that could predict survival in our patient group. With the appropriate Cox regression model shown in table 3 we were finally able to extract two main informations: Firstly, the model proves the influence of QoL measured with the FACT-G core instrument. This clearly supports our above-mentioned hypothesis. Since the measurement of HRQoL with the FACT-G instrument is wellestablished and widely used, there are no serious doubts about this result.

However, our results contrast with the findings of Meyers et al. [22], who state that the results of neuropsychological testing and not QoL scores (assessed with FACT-BR) predict survival. At first sight, these two results are contradictory. However, one must take into account the differences in patient selection: Meyers et al. [22] focused on patients with recurrent disease, excluding patients with metastases. They explicitly included patients with severe cerebral deficits which were excluded by the study protocol in our work. This resulted in a quota of $15 \%$ of their patients not completing the applied quality of life instrument. Considering these findings and es- 
pecially the absence of severe neuropsychological and cerebral deficits in our patient sample, these differences might well be attributed to patient selection.

When performing a correlation analysis between the FACT-G scales and KPS, significant correlations can indeed be measured. Such is the case only at the initial point of measurement at the scales for physical well-being (correlation coefficient (CC) 0.344, p = 0.01), emotional well-being (CC 0.302, p $=0.024)$, functional well-being $(\mathrm{CC} 0.419, \mathrm{p}=0.001)$ and for the sum score (CC 0.381, p = 0.004). Although significant, these correlations are very moderate; none of them even reaches beyond the level of 0.5 . Thus, this fact does not leave much space for interpretation as correlations are too weak to build a lucid argumentation on it. In spite of these moderate correlations, we omitted KPS in our model to increase its interpretability.

An additional point that has to be clarified is the use of the factor 'living with one's spouse' instead of the marital status: In the past, being married implicitly meant that one was living together with the partner, and being single meant one was liv- ing alone. Today, this has changed in western societies: In persons below 40 years, more and more people live together with their spouse without being married. Thus we decided that this direct approach might be more appropriate to gather information about the situation in reality than the abstract marital status.

Health-related QoL is becoming more and more important, especially for patients facing death from their disease. It can serve not only to distinguish patients with a longer expected survival rate from those who might be facing a sooner death but also to estimate the patient's survival time.

Subjective measurements of how patients facing a fatal outcome from brain neoplasm feel, how they deal with life and the disease and their psychosocial state as a whole, obviously carry a greater potential for prolonged life than standard somatic factors [23]. It is essential that our findings are applied to a larger sample of patients to go beyond the natural limitations of a pilot study and that other investigators also elucidate the question whether successful attempts to improve quality of life can promote prolonged survival.

\section{References}

1 Faller H, Bülzebuck H, Schilling S, Drings P, Lang $\mathrm{H}$ : Beeinflussen psychologische Faktoren die Überlebenszeit bei Krebskranken? Ergebnisse einer empirischen Untersuchung mit Bronchialkarzinomkranken. Psychother Psychosom med Psychol 1997; 47:206-218.

2 Andersen BL: Surviving cancer. Cancer 1994;74 (suppl 4):1484-1495

3 Fox B: Psychosocial factors in cancer and influence on prognosis; in Holland JC (ed): Handbook of Psychooncology. New York, Oxford University Press, 1998, pp 110-123.

4 Huerny C: Psychologische und Psychosoziale Faktoren in Entstehung und Verlauf maligner Erkrankungen; in Uexküll T (ed): Psychosomatische Medizin, ed 5. München, Urban und Schwarzenberg, 1996 pp 953-969.

5 Fisk JL, Del Dotto JE: Neuropsychological sequelae of brain tumors. Henry Ford Hosp Med J 1990; 38:213-218.

6 Leibel SA, Hutin PH, Wara WM: Survival and quality of life after interstitial implantation of removable high-activity iodine- 125 sources for the treatment of patients with recurrent malignant gliomas Int J Radiat Oncol Biol Phys 1989;17:1129-1139.

7 Choucair AK, Scott C, Urtasun R, Nelson D, Mousas B, Curran W: Quality of life and neuropsychological evaluation for patients with malignant astrocytomas: RTOG 91-14. Int J Radiat Oncol Biol Phys 1997;38:9-20.

8 Bampoe J, Laperriere N, Pintilie M, Glen J, Micallef J, Bernstein M: Quality of life in patients with glioblastoma multiforme participating in a randomized study of brachytherapy as a boost treatment. J Neurosurg 2000;93:917-926.
9 Giovagnoli AR, Tamburini M, Boiardi A: Quality of life in brain tumor patients. J Neurooncol 1996; 30:71-80.

10 Kiebert GM, Curran D, Aaronson NK, Bolla M, Menten J, Rutten EH, Nordman E, Silvestre ME, Pierart M, Karim AB: Quality of life after radiation therapy of cerebral low-grade glioma of the adult: Results of a randomized phase III trial on dose response. Eur J Cancer 1998;34:1902-1909.

11 Cella DF, Tulsky DS, Gray G, Sarafian B, Linn E, Bonomi A, Silberman M, Yellen SB, Winicour P, Brannon J: The Functional Assessment of Cancer Therapy scale: Development and validation of the general measure. J Clin Oncol 1993;11:570-579.

12 Weitzner M, Meyers C, Gelke CK, Byrne KS, Cella DF, Levin VA: The functional assessment of Cancer therapy (FACT) Scale. Development of a brain subscale and revalidation of the general version (FACT-G) in patients with primary brain tumors. Cancer 1995;75:1151-1161.

13 Coates AS, Hürny C, Peterson HF, Bernhard J, Castiglione-Gertsch M, Gelber RD, Goldhirsch A: Quality-of-life scores predict outcome in metastatic but not early breast Cancer. J Clin Oncol 2000;18: 3768-3774.

14 Sehlen S, Hollenhorst H, Schymura B, Song R, Aydemir U, Steinbuchel NV, Duehmke E: Radiotherapy: Impact of quality of life and need for psychological care: Results of a longitudinal study. Onkologie 2000;23:565-570.

15 Sehlen S, Hollenhorst H, Lenk M, Schymura B, Herschbach P, Aydemir U, Duhmke E: Only sociodemographic variables predict quality of life (QoL) after radiotherapy in patients with head and neck cancer. Int J Radiat Oncol Biol Phys 2002;52: 779-783.
16 Coleman MP, Babb P, Sloggett A: Socioeconomic inequalities in cancer survival in England and Wales. Cancer 2001;91:208-216.

17 Herschbach P: Das Zufriedenheitsparadox in der Lebensqualitätsforschung - wovon hängt unser Wohlbefinden ab? Psychother Psychosom Med Psychol 2002;52:141-150.

18 Weimann A, Müller MJ, von Herz U, Arends J, Dörries A, Keymling M, Kürmayr M, Nagel E: Lebensqualität als Kriterium des Erfolgs einer künstlichen Ernährung - Loccumer Gespräche 1998. Intensivmedizin 1998;35:724-726.

19 Bradley C: Importance of differentiating health status from quality of life. Lancet 2001;357:7-8.

20 Davies E, Clarke C, Hopkins A: Malignant cerebral glioma - perspectives of patients and relatives on the value of radiotherapy. Br Med J 1996;313: 1512-1516.

21 Kreitler S, Chaitchnik S, Rapoport Y, Algor R: Life satisfaction and health in cancer patients, orthopaedic patients and healthy individuals. Soc Sci Med 1993; 36:547-556.

22 Meyers CA, Hess KR, Yung WKA, Levin VA: Cognitive function as a predictor of survival in patients with recurrent malignant glioma. J Clin Oncol 2000;18:646-650.

23 Mulder CL: Do psychosocial factors influence the course of breast cancer: A review of recent literature, methodological problems and further direction. Psychooncology 1992;1:155-167. 